\title{
Industrial and Occupational Employment Changes During the Great Recession
}

\author{
Sangmin Aum, Sang Yoon (Tim) Lee, and Yongseok Shin
}

The U.S. labor market contracted sharply during the Great Recession. The ensuing recovery has been sluggish and by some measures still incomplete. In this paper, we break down aggregate employment during the Recession and the recovery into changes across industries and occupations. There is a clear asymmetric pattern: The contraction is driven by sectors and the recovery by occupations. In particular, the contraction between 2008 and 2010 primarily reflects a steep decline in construction employment, partially mitigated by expansions in the food services, education, and health industries. The recovery first came from a gradual increase in low-skill occupation employment across all sectors but after 2012 from a pronounced increase in high-skill occupation employment across all sectors. This pattern of recovery is a continuation of the underlying trend of polarization across occupations, which commenced in the 1980s. (JEL E32, J62)

Federal Reserve Bank of St. Louis Review, Fourth Quarter 2017, 99(4), pp. 307-17. https://doi.org/10.20955/r.2017.307-317

\section{INTRODUCTION}

The Great Recession left a deep, persistent mark on the U.S. labor market. By October 2009 , the unemployment rate shot up to 10 percent from its pre-recession level of 5 percent in as late as April 2008. The recovery was painfully slow-it was not until October 2015 that the unemployment rate returned to its pre-recession level. Other measures of the labor market-for example, total hours worked and payroll—tell the same story.

There has been no shortage of commentary and academic papers on the slow recovery of the labor market that followed the Great Recession. But most focus on aggregate, or economywide, statistics. Some do explore changes in employment across industrial sectors, but few attempt to dissect employment fluctuations across occupations. 1 In this paper, we consider employment changes across industries and occupations jointly, aiming to provide further insights on the labor market dynamics during and after the Great Recession. $\underline{2}$

Sangmin Aum is a PhD candidate in economics at Washington University in St. Louis. Sang Yoon (Tim) Lee is an assistant professor at Toulouse School of Economics. Yongseok Shin is a professor of economics at Washington University in St. Louis and a research fellow at the Federal Reserve Bank of St. Louis. The authors thank two anonymous referees for many helpful comments.

○ 2017, Federal Reserve Bank of St. Louis. The views expressed in this article are those of the author(s) and do not necessarily reflect the views of the Federal Reserve System, the Board of Governors, or the regional Federal Reserve Banks. Articles may be reprinted, reproduced, published, distributed, displayed, and transmitted in their entirety if copyright notice, author name(s), and full citation are included. Abstracts, synopses, and other derivative works may be made only with prior written permission of the Federal Reserve Bank of St. Louis. 
We use the American Community Survey (ACS), which has a large enough sample size that enables a detailed industrial and occupational level analysis of the labor market. One shortcoming is that it is annual data and hence not suitable for higher-frequency (i.e., monthly and quarterly) business-cycle analysis. However, for our study of the Great Recession, which is a big, discontinuous event, annual data may still produce a conspicuous pattern. Indeed, our analysis finds a striking, hitherto undocumented pattern.

We find that the sharp contraction in the labor market during the Great Recession was largely driven by the construction sector, which shed employment across all occupations. This was only partially mitigated by rising employment in the food services, education, and health industries, which added workers and hours across all occupations.

In contrast, the recovery since 2010 is not led by particular industries but by low-skill occupations (between 2010 and 2012) and high-skill occupations (after 2012) across all industries. This pattern of recovery is a continuation of the underlying trend of polarization across occupations-employment moving away from middle-skill occupations to low- and high-skill ones-that started in the 1980s. $\frac{3}{3}$

This "contraction by sectors and expansion by occupations" asymmetry has never been documented and is a worthwhile observation in its own right. We conjecture, however, that the sharp contraction along the sector dimension and the ensuing slow rise along the occupation dimension will eventually offer an insight into the slow recovery from the Great Recession and, more broadly, the negative skewness of business cycle fluctuations (i.e., sudden recessions and slow recoveries).

The rest of the paper is organized as follows. We describe the data and define the employment shares of interest in Section 2. In Section 3, we show employment changes at the occupation level and decompose them into between- and within-sector components. In Section 4, we show employment changes across industrial sectors. We follow up in Section 5 with a detailed look at year-to-year changes in employment for selected sectors, breaking down a sector's employment change by occupations of different skill levels. Finally, we summarize our findings and discuss avenues for future research in Section 6.

\section{DATA}

Employment shares by occupation and industry are constructed from the 2000 Census and the 2001 to 2015 ACSs. We restrict our sample to 16 to 64 year olds who report themselves as employed at the time of each survey. We measure employment in each industryoccupation combination by summing up the hours worked (over a year) of all workers in a given industry-occupation cell. $\stackrel{4}{ }$ That is, by employment, we mean total hours worked-or, equivalently, hours per worker times the number of workers. Hence in our analysis, a fall in employment occurs along both the intensive (change in hours only) and extensive (change in the number of workers) margins. Accordingly, the employment share of an industry (or an occupation) means total hours worked in an industry (or occupation) divided by total hours in the entire sample. 
We include self-employed workers when computing employment, but exclude them when computing average wages by occupation or industry. We exclude agricultural occupations and industries, although their inclusion does not affect our main results.

Consistent occupational codes can be constructed for the 2000-14 period using the OCC2010 variable provided by the Integrated Public Use Microdata Series (IPUMS). We work with a balanced panel of 425 occupations.

For industry codes, we use two classifications. First, we modify the IND1990 variable in the IPUMS into 209 industries that are balanced across all years, which we use in our decomposition of occupational employment shares into between- and within-industry components (Section 3). Second, when we compute employment shares by industry, we collapse the INDNAICS variable to 61 industries to be consistent with the Bureau of Economic Analysis industry codes.

\section{EMPLOYMENT CHANGES BY OCCUPATION}

We first define the variables used in our empirical analysis. Let $l_{i, j, t}$ be the employment (i.e., total hours) for occupation $i$ in industry $j$ in year $t$. Consistent with this notation, $l_{j, t}$ is employment in industry $j$ in year $t\left(l_{i, j, t}\right.$ summed across all occupations $)$ and $l_{t}$ is total employment in year $t\left(l_{i, j, t}\right.$ summed across all occupations and industries).

The employment share of occupation $i$ is given by

$$
\sigma_{i, t}=\sum_{j \in J} \frac{l_{i, j, t}}{l_{j, t}} \times \frac{l_{j, t}}{l_{t}}
$$

Then the employment-share change of occupation $i$ from year $s$ to $t$ can be expressed as

$$
\Delta \sigma_{i, t}=\underbrace{\sum_{j \in J} \Delta\left(\frac{l_{i, j, t}}{l_{j, t}}\right) \times \overline{\left(\frac{l_{j}}{l}\right)}}_{\text {within industry }}+\underbrace{\sum_{j \in J} \Delta\left(\frac{l_{j, t}}{l_{t}}\right) \times \overline{\left(\frac{l_{i, j}}{l_{j}}\right)}}_{\text {between industry }},
$$

where $\Delta\left(x_{t}\right) \equiv\left(x_{t}-x_{s}\right) /(t-s)$ and $\overline{(x)} \equiv\left(x_{t}+x_{s}\right) / 2$.

Figure 1 shows the changes in occupational employment shares and decomposes them into within- and between-industry components. There are four plots, each corresponding to a different subperiod: 2000-08 represents the pre-existing trend, $\underline{5}$ 2008-10 the Great Recession, 2010-12 the beginning of the recovery, and 2012-14 the fuller phase of recovery.

For each plot (from year $s$ to $t$ ), we order occupations on the $x$-axis by their average log hourly wage in the base year $s$. We consider occupational mean wages as a measure of skill, so low-skill occupations are to the left and high-skill occupations to the right. Occupations are grouped into deciles, so that each group accounts for exactly 10 percent of total employment in the base year. $\underline{6}$

For each occupation decile, a dot denotes the percentage-point change of that group's employment share from year $s$ to $t$, annualized (i.e., divided by $t-s$ ) for comparability across 


\section{Figure 1}

\section{Changes in Employment Shares Across Occupations}

\section{A. 2000-08}

Percentage Point Change in the Employment Share (annualized)
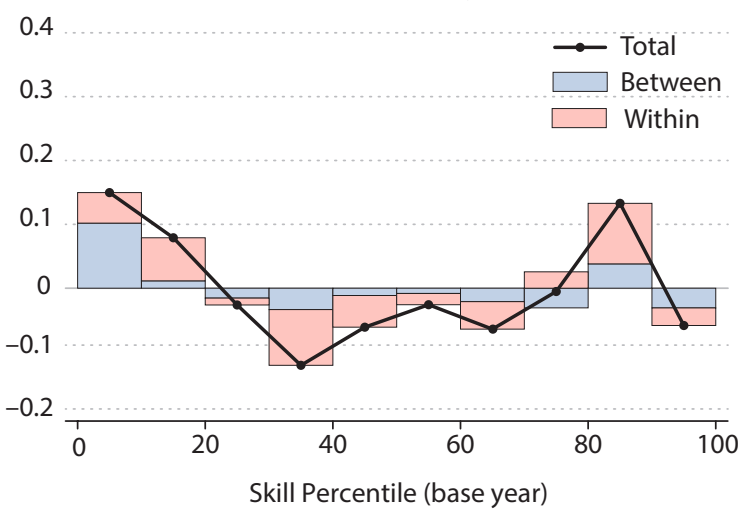

C. 2010-12

Percentage Point Change in the Employment Share (annualized)
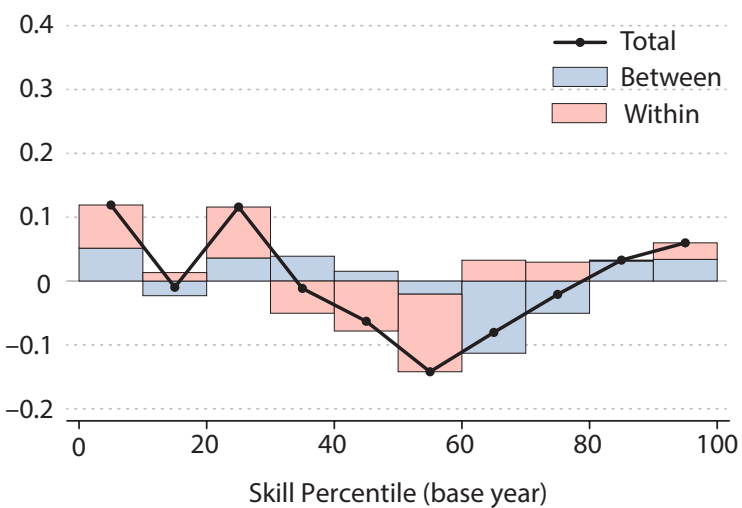

\section{B. 2008-10}

Percentage Point Change in the Employment Share (annualized)

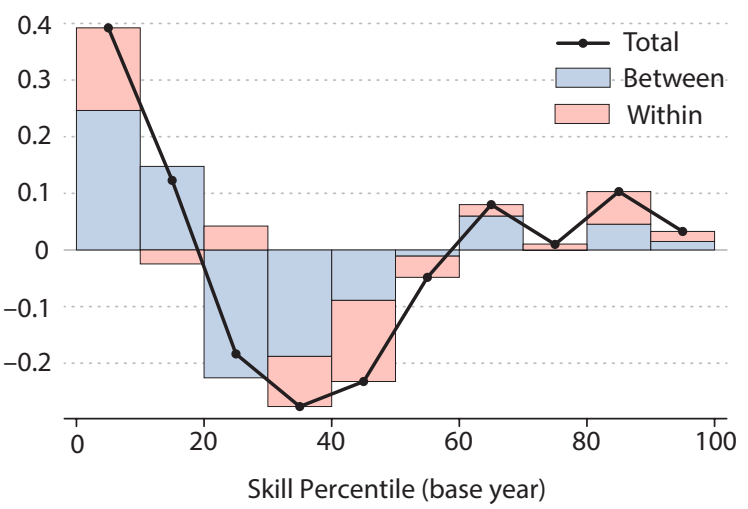

D. 2012-14

Percentage Point Change in the Employment Share (annualized) 0.4

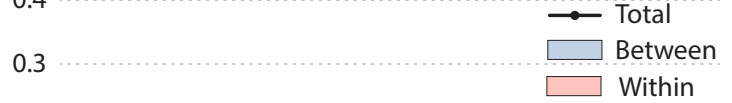

0.2

0.1

0

0.1

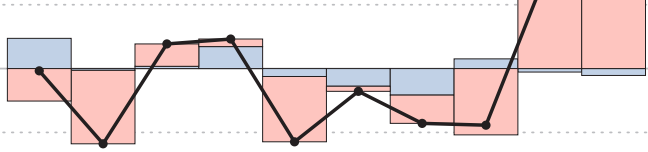

$-0.2$

0

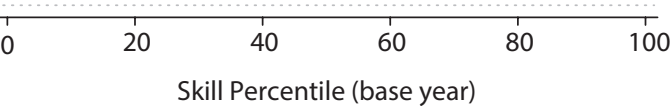

SOURCE: Authors' calculations from the 2001 to 2015 ACSs.

subperiods. The red portion of a bar depicts the percentage-point increase (above 0 ) or decrease (below 0 ) attributable to the within-industry component and the blue portion to the betweenindustry component. The sum of the two coincides with the dot.

For example, take the leftmost bar in Figure 1A. It shows that the employment share of the lowest mean-wage occupations, which started at 10 percent in 2000 and grew by about 0.15 percentage points per year up to 2008. Of the 0.15 -percentage-point increase per year, 0.10 is the between-industry component (i.e., a shift in employment from industries that employ few low-wage occupations to those that employ relatively more low-wage occupations) and the remaining 0.05 is the within-industry component (i.e., an increase in employment in lowwage occupations across all industries). 
The following summarizes the key empirical patterns shown in Figure 1:

1. Throughout the 2000-14 period, occupational employment share changes are consistent with the well-established notion of polarization since the 1980s. Employment shares grew for high-wage and low-wage occupations, while they contracted for middle-wage occupations. For example, the bottom 20 percent and the top 20 percent of occupations ranked by mean wages in the year 2000 gained 4.6 percentage points of the employment share between 2000 and 2014.

2. The between-industry component (in blue) was dominant during the Great Recession. In all other periods, the within-industry component is more important. More precisely, 64 percent of occupational employment changes is attributed to the between-industry component during the Great Recession (2008-10), whereas it accounts for only 35 percent in all other periods on average.

3. The biggest (annualized) changes in occupational employment shares took place between 2008 and 2010 and then between 2012 and 2014. The 2008-10 subperiod is characterized by a significant fall in the employment shares of middle-wage occupations, offset by a rise among low-wage occupations. The between-industry component explains most of this change, implying that sectors that employ relatively more middle-wage occupations contracted and those employing relatively more low-wage occupations expanded.

4. The 2012-14 subperiod exhibits a strong employment gain among high-wage occupations, accompanied by falling employment shares among both low- and middle-wage occupations. Nearly all the changes are attributable to the within-industry component, indicating that this development occurred broadly across all sectors.

Because of the preponderance of the between-industry component-indicating sectorspecific changes in the labor market during the Great Recession-we now turn to a direct measure of employment changes across sectors.

\section{EMPLOYMENT CHANGES BY INDUSTRY}

As defined in Section 3, employment in an industry is the total hours worked by all workers in that industry. Employment in industry $j$ in year $t$ is denoted as $l_{j, t}$. The employment share of industry $j$ is $l_{j, t}$ divided by aggregate employment (total employment across all industries) in year $t, l_{t}$.

In Figure 2, we plot the employment share changes across 61 industrial sectors over the 2000-14 period, again divided into the same four subperiods as in Figure 1.

We order industries by their average log hourly wage in the base year, ascending from left to right. $\underline{Z}$ In each plot (from year $s$ to $t$ ), a bar represents the annualized percentage-point change in the employment share of a given industry from year $s$ to year $t$. The width of each industry bar is the employment share of the given industry (in percent) in the base year.

For example, the leftmost bar in Figure $2 \mathrm{~A}$ is for the industrial category of food services and drinking places, which had the lowest mean wage of all industries in 2000 . The bar width is its employment share in 2000, 4.1 percent, and the bar height is the annualized change in its employment share from 2000 to 2008, an increase of 0.07 percentage points per year. 


\section{Figure 2}

\section{Changes in Employment Shares Across Industries}

\section{A. 2000-08}

Percentage Point Change in the Employment Share (annualized)

0.2

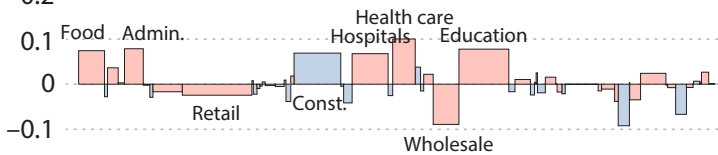

$-0.2$

$-0.3$

$-0.4$

$-0.5$

$-0$.

0.6

Employment Share in Base Year (sorted by average wage)

\section{2010-12}

Percentage Point Change in the Employment Share (annualized) 0.2

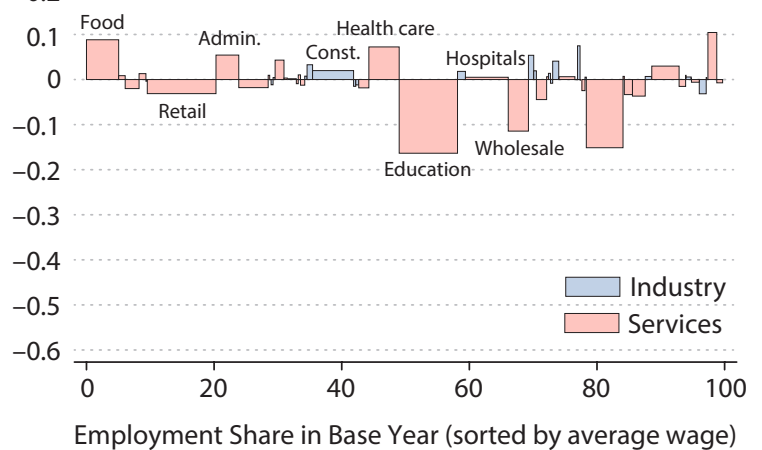

\section{B. 2008-10}

Percentage Point Change in the Employment Share (annualized)

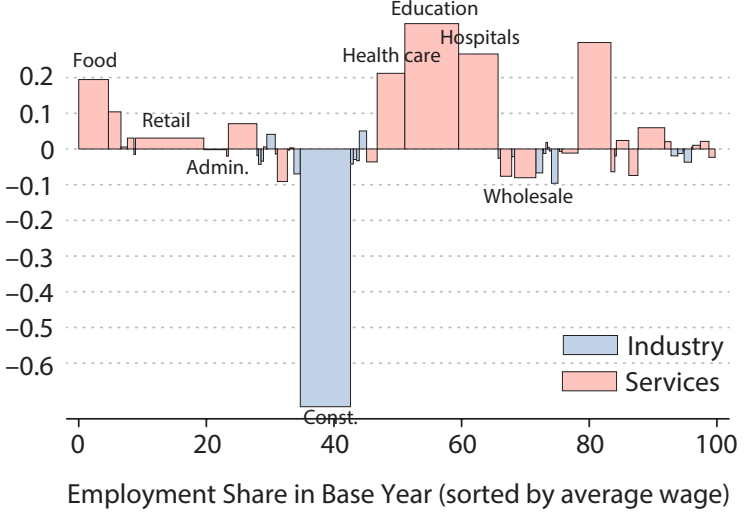

\section{2012-14}

Percentage Point Change in the Employment Share (annualized) 0.2

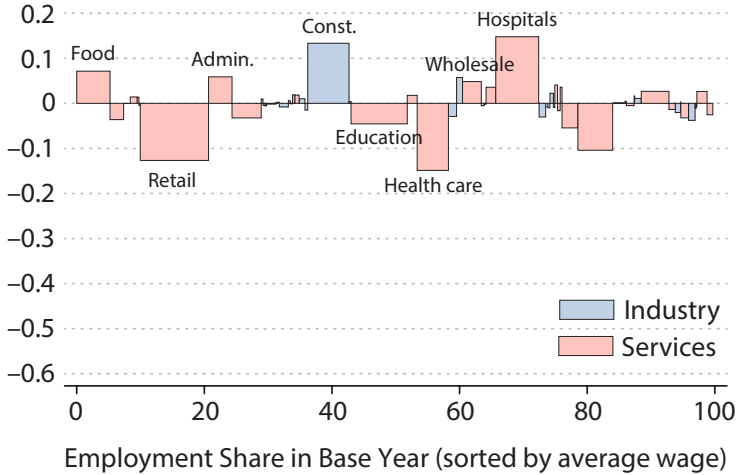

NOTE: Admin., administrative and support services. Const., construction. Education, educational services. Food, food services and drinking places. Health care, ambulatory health care services. Hospitals, hospitals and nursing and residential care facilities. Retail, retail trade. Wholesale, wholesale trade.

SOURCE: Authors' calculations from the 2001 to 2015 ACSs.

The following summarizes some noticeable patterns that emerge from Figure 2:

1. The most salient fact is that employment shifts across industries were much more prominent during the Great Recession than usual. In particular, 40 percent of the employment share losses is concentrated in one industry-construction-out of 31 industries with declining employment shares. .8 Because we are plotting changes in employment shares, this loss will show up as gains in other sectors. Most of the gains are accounted for by food services, education, and hospitals/nursing/residential care facilities. These 
industries gained employment in absolute terms as well, even as aggregate employment was declining during the Recession.

2. Both before and after the Great Recession, it is difficult to discern any clear pattern in employment-share changes across industries. One observation is that the employment shares of the food and hospital industries persistently rose throughout the sample period (also see Section 5). Another is that industries such as retail, education, and, of course, construction have more volatile employment shares than the rest.

3. While not as conspicuous, there is an underlying trend of structural transformation from manufacturing to services throughout the entire sample period. For example, the service sector gained 4.2 percentage points of the employment share between 2000 and 2014.

\section{EMPLOYMENT CHANGES BY OCCUPATION: SELECTED INDUSTRIES}

In this section, we complement the preceding analyses in two ways. First, we summarize changes in employment levels, rather than shares, to see how the large drop in aggregate employment during the Great Recession was distributed across different occupations and industries. Second, for selected industries of interest (those that experienced large changes), we examine how different occupations contributed to each industry's employment change (by level) over the Great Recession period. This information is absent in Sections 3 and 4.

Here we measure employment by the number of workers, regardless of full- or part-time status. Let $n_{i, j, t}$ denote the number of workers for occupation $i$ in industry $j$ in year $t$. Then $\left(n_{i, j, t}-n_{i, j, s}\right) /(t-s)$ measures the annualized change in employment for occupation $i$ in industry $j$ from year $s$ to year $t$.

While we use the same 61 industry classifications, we group occupations in a different way from Section 3. We rank the 425 occupations by their 1999 mean wage and divide them into five groups. So each group accounts for exactly 20 percent of aggregate employment in 2000 , with the first (or last) group comprising the lowest (or highest) mean-wage occupations. Unlike in Section 3, we fix this occupation grouping across all subperiods.

Figure $3 \mathrm{~A}$ shows the annualized changes in aggregate employment (number of workers), and Figures $3 \mathrm{~B}$ to $3 \mathrm{D}$ show the changes for three industries of interest: construction, hospitals,

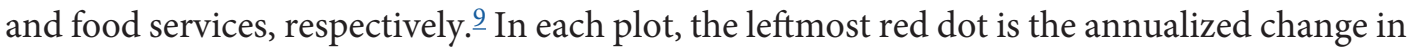
employment from 2000 to 2008 (in millions), and the other dots are the year-by-year changes from 2008 to 2014. The colored bars then break down these changes into the five occupation wage groups (from dark to light, in ascending order of skills measured by the occupational mean wage in 1999).

For example, take the bar 09-10 in Figure 3A, which is the change in aggregate employment from 2009 to 2010. The location of the red dot indicates that aggregate employment shrank by 1.6 million. This number, however, masks the fact that some occupations actually gained employment in spite of the overall contraction. The darkest part of the bar shows that the lowest-wage occupation quintile added 0.4 million workers, while the other four wage 


\section{Figure 3}

\section{Changes in Employment by Occupation Within Selected Industries}

\section{A. All Industries}

Changes in Employment (annualized, millions)

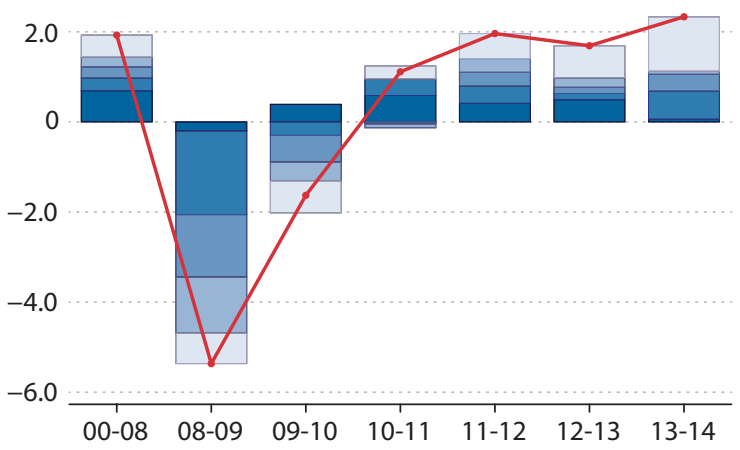

\section{Hospitals}

Changes in Employment (annualized, millions)

0.4

0.3

0.2

0.1

0

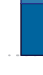

$-0.1$

00-08 $08-09 \quad 09-10 \quad 10-11 \quad 11-12 \quad 12-13 \quad 13-14$

0-20 Percent
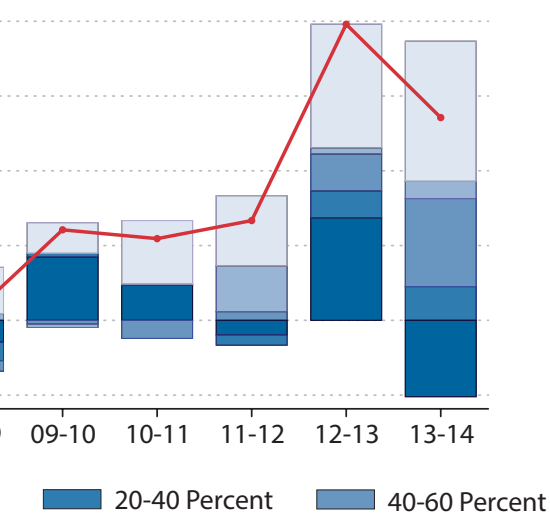

\section{B. Construction}

Changes in Employment (annualized, millions)

0.5

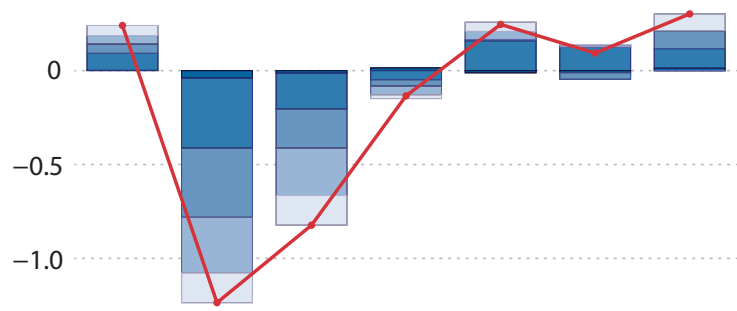

1.5

\section{Food Services}

Changes in Employment (annualized, millions)

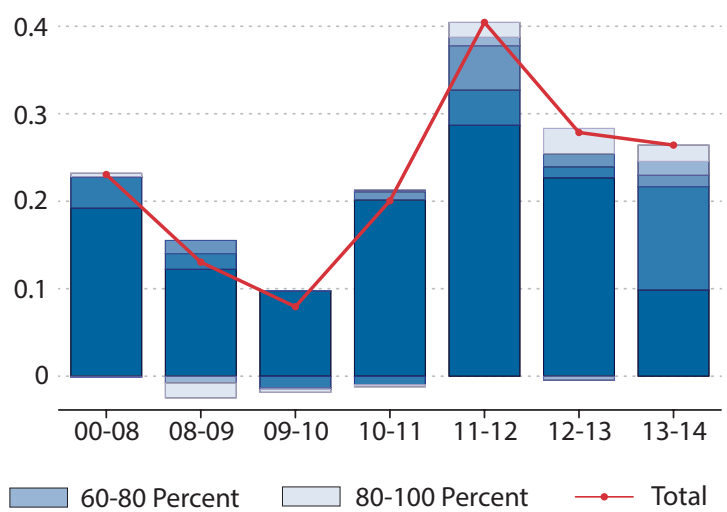

SOURCE: Authors' calculations from the 2001 to 2015 ACSs.

Figure 1B, which showed large employment share gains for the low-wage occupations during the Great Recession.

Some important features in Figure 3 are as follows:

1. Figure 3A shows that between 2008 and 2010, aggregate employment (as measured by the number of workers) fell by 7 million, or 5 percent, from a peak of 138 million in 2008. All but the lowest-wage occupation quintile lost employment, with the second quintile taking the biggest hit. Consistent with what we observed in Section 3, the lowestwage occupation group leads the recovery till 2011, followed by the highest-wage occupation group in later years. 
2. From Section 4 we know that the construction sector bore the brunt of the Great Recession. Figure 3B shows that it shed more than 2 million workers between 2008 and 2010. This represents a 20 percent drop in employment from its peak of 10 million in 2008. Also, the 2 -million-worker loss in construction is nearly 30 percent of the number of workers lost in aggregate (7 million). It also shows that within the construction sector, employment dropped across all occupation groups. The moderate recovery since 2011 is attributable to middle-wage occupations. At the end of 2014, employment in the construction sector is still 15 percent below its 2008 peak.

3. As shown by the red dots in Figures $3 \mathrm{C}$ and 3D, hospitals and food services did not lose employment even during the Great Recession. However, different occupation-wage groups led the employment growth of the two sectors. Hospital employment rose by 1 million between 2008 and 2014 (or by 12 percent of its employment in 2008, 8.6 million). Of this, 0.6 million is accounted for by the highest-wage occupation group. On the other hand, food services added 1.4 million workers between 2008 and 2014 (a 17 percent increase from 7.9 million in 2008), of which 1 million (or 76 percent) belongs to the lowest-wage occupation group. $\frac{10}{}$ Another interesting difference is that the fraction of part-time workers in the highest-wage occupation group in the hospital industry fell from 21.1 percent to 18.4 percent, whereas the fraction of part-time workers in the lowest-wage occupation group in food services increased from 57.7 percent to 59.8 percent. $\frac{11}{11}$

\section{CONCLUDING REMARKS}

Employment dropped sharply during the Great Recession, followed by a slow recovery. Both the contraction and the recovery were unevenly distributed across different industries and occupations. We reveal some new, interesting facts by tracking employment changes within and between industry-occupation groups. The sharp contraction was concentrated in the construction sector, but the recovery does not display any clear pattern of employment shifts among sectors. Instead, it is initially driven by low-skill and later (since 2012) by highskill occupations, more or less across all sectors. We conjecture that this may shed new insights into the cause and mechanics of the sluggish recovery from the Great Recession.

In this paper, we focused strictly on employment shifts of a given industry-occupation group, abstracting from how individual workers actually transition from one group to another. In separate ongoing work, we find that the employment share changes across industries and occupations do not necessarily reflect individual workers switching industries or occupations. For example, while the contraction of the construction sector affected young workers with no college education the most, the concurrent expansion of employment in food services is largely explained by older workers with no college education. (That is, they are different people.) This points to sector- and occupation-specific human capital and also frictional labor markets, which we will address in our future research. 


\section{Aum, Lee, Shin}

\section{NOTES}

1 Notable exceptions are Smith (2013), Tüzemen and Willis (2013), Cortes et al. (2015), Foote and Ryan (2015), Jaimovich and Siu (2015), and Shim and Yang (2016).

2 Foote and Ryan (2051) suggest that sectoral components may be important for understanding the cyclical volatility of middle-skill occupations, because many of them are employed in volatile sectors, for example, construction and manufacturing. Lee and Shin (2017) develop a model that integrates the industrial and occupational structure of the economy but analyzes longer-term trends and not cyclical fluctuations. For the rest of the paper, we use "sector" and "industry" interchangeably.

$\underline{3}$ One of the earlier papers to notice this trend is Autor, Levy, and Murnane (2003).

4 We closely follow the literature in the data-cleaning procedure. For example, we impute missing hours from workers with the same educational attainment and occupation, following Autor, Katz, and Kearney (2008). Discarding all missing values or changing age cutoffs, however, has virtually no impact on the results reported in the paper.

5 One might wonder whether the time aggregation over 2000-08 introduces some bias. When we broke down this eight-year interval into four two-year intervals, we found no meaningful deviation from the main points of our paper, either in terms of magnitude or the composition of within-versus between-industry changes.

6 In order to keep each group representing exactly 10 percent of the total labor supply, we change the base year for every calculation. For example, the deciles in the Great Recession period (2008-10) are based on the 2007 wage distribution. This way, we see the changes in employment structure in a consistent manner. Fixing the occupation grouping according to the 1999 wage distribution, however, does not materially change our main result, because not many occupations jumped across deciles over the sample period.

$\geq$ Although we reorder industries by their average wage for each subperiod, their rankings change very little over the entire sample period.

8 In 2008, by comparison, construction accounted for 20 percent of employment among the same 31 industries.

9 One might think that hospitals and health services are similar services and hence could be combined together. However, they differ not only in the average wage of their workers but also in their employment response during the Great Recession.

10 This should be considered in conjunction with the fact that food services intensively use low-wage occupations. In 2008, the lowest-wage occupation group accounted for 81 percent of all employment in food services.

11 A worker is classified as part time if he works less than 35 hours per week or less than 40 weeks in a year.

\section{REFERENCES}

Autor, David H.; Katz, Lawrence F. and Kearney, Melissa S. "Trends in U.S. Wage Inequality: Revising the Revisionists." Review of Economics and Statistics, May 2008, 90(2), pp. 300-23; https://doi.org/10.1162/rest.90.2.300.

Autor, David H.; Levy, Frank and Murnane, Richard J. "The Skill Content of Recent Technological Change: An Empirical Exploration." Quarterly Journal of Economics, Oxford University Press, 2003, 118(4), pp. 1279-333; https://doi.org/10.1162/003355303322552801.

Cortes, Guido M.; Jaimovich, Nir; Nekarda, Christopher J. and Siu, Henry E. "The Micro and Macro of Disappearing Routine Jobs: A Flows Approach." Unpublished manuscript, July 21, 2015; http://faculty.arts.ubc.ca/hsiu/work/micro macro 20150717.pdf.

Foote, Christopher L. and Ryan, Richard W. "Labor Market Polarization over the Business Cycle," in J.P. Parker and M. Woodford, eds., NBER Macroeconomics Annual. Volume 29. Chicago: University of Chicago Press, 2015, pp. 371-413; https://doi.org/10.3386/w21030.

Jaimovich, Nir and Siu, Henry E. "Job Polarization and Jobless Recoveries." Unpublished manuscript, May 2015; http://econ.arts.ubc.ca/hsiu/research/polar20150503.pdf.

Lee, Sang Yoon and Shin, Yongseok. "Horizontal and Vertical Polarization: Task-Specific Technological Change in a Multi-Sector Economy." NBER Working Paper No. 23283, National Bureau of Economic Research, March 2017. 
Aum, Lee, Shin

Shim, Myungkyu and Yang, Hee-Seung. "New Stylized Facts on Occupational Employment and Their Implications: Evidence from Consistent Employment Data." Economic Modelling, December 2016, 59(C), pp. 402-15; https://doi.org/10.1016/j.econmod.2016.08.006.

Smith, Christopher L. "The Dynamics of Labor Market Polarization." Finance and Economics Discussion Series 2013-57, Board of Governors of the Federal Reserve System, 2013; https://www.federalreserve.gov/pubs/feds/2013/201357/201357pap.pdf.

Tüzemen, Didem and Willis, Jonathan L. "The Vanishing Middle: Job Polarization and Workers' Response to the Decline in Middle-Skill Jobs." Federal Reserve Bank of Kansas City Economic Review, Quarter 1 2013, 98(1), pp. 5-32. 
